\title{
Reliability-Based Design Optimization for Crane Metallic Structure Using ACO and AFOSM Based on China Standards
}

\author{
Xiaoning Fan and Xiaoheng Bi \\ Mechanical Engineering College, Taiyuan University of Science and Technology, Taiyuan, Shanxi 030024, China \\ Correspondence should be addressed to Xiaoning Fan; fannyfxn@163.com
}

Received 9 July 2014; Revised 4 January 2015; Accepted 19 January 2015

Academic Editor: Paolo Lonetti

Copyright (C) 2015 X. Fan and X. Bi. This is an open access article distributed under the Creative Commons Attribution License, which permits unrestricted use, distribution, and reproduction in any medium, provided the original work is properly cited.

\begin{abstract}
The design optimization of crane metallic structures is of great significance in reducing their weight and cost. Although it is known that uncertainties in the loads, geometry, dimensions, and materials of crane metallic structures are inherent and inevitable and that deterministic structural optimization can lead to an unreliable structure in practical applications, little amount of research on these factors has been reported. This paper considers a sensitivity analysis of uncertain variables and constructs a reliability-based design optimization model of an overhead traveling crane metallic structure. An advanced first-order second-moment method is used to calculate the reliability indices of probabilistic constraints at each design point. An effective ant colony optimization with a mutation local search is developed to achieve the global optimal solution. By applying our reliability-based design optimization to a realistic crane structure, we demonstrate that, compared with the practical design and the deterministic design optimization, the proposed method could find the lighter structure weight while satisfying the deterministic and probabilistic stress, deflection, and stiffness constraints and is therefore both feasible and effective.
\end{abstract}

\section{Introduction}

As tools for moving and transporting goods, cranes are used in various settings to aid the development of economy and undertake the heavy logistical handling tasks in factories, railways, ports, and so on. Metallic structure is mainly made out of rolled merchant steel and plate steel by welding method according to certain structural organization rules. Crane metallic structures (CMSs), also called crane bridge, bear and transfer the burden of crane and their own weights. CMSs are mechanical skeleton and form the main components of cranes. Their design qualities have direct impact on the technical and economic benefit, as well as the safety, of the whole crane.

Generally, a CMS requires a large quantity of steel and consequently weighs a considerable amount. Its cost accounts for over a third of the total cost of the crane. Thus, under the condition of satisfying the relevant design codes, improving the performances of the CMS, saving material, and reducing weight have important significance in terms of cost-savings. As a consequence, various scholars have researched on this problem, and current optimization methods mainly include finite element method [1], neural networks [2], and Lagrange multipliers [3], amongst others [4-6]. However, these methods are all based on deterministic optimum designs and do not consider the effect of randomness in the structure and/or load. Studies have shown that the loads effected on the CMS, and the materials and geometric dimensions of the structure itself are uncertain. Deterministic optimum designs are pushed to the limits of their constraints boundaries, leaving no room for uncertainty. Optimum designs obtained without consideration of such uncertainties are therefore unreliable $[7,8]$. Recently there have been a few reports about reliability-based design of crane structure $[9,10]$. Literature [9] researched on the reliability-based design of structure of tower crane based on the finite element analysis (FEA) and response surface method (RSM). Meng et al. [10] analyzed the reliability and sensitivity of crane metal structure by means of BP neural network based on finite element and first-order second-moment (FOSM) method. Nevertheless, design only considering reliability could not guarantee the best work performance and the optimal design parameters. 
The aim of a design is to achieve adequate safety at minimum cost under the condition of meeting specified performance requirements. Hence, the optimization based on reliability concepts appears to be a more rational design philosophy, which is why reliability-based design optimization (RBDO) has been developed. RBDO incorporates the optimization of design parameters and reliability calculations for specified limit states. At present, it is attracting increased attention, both in theoretical research and practical applications [1113]. Despite advances in this area, few RBDO approaches specific to CMS have appeared in the technical literature. Therefore, this paper develops an RBDO methodology for optimizing CMS that both minimizes the weight and guarantees structural reliability. The main structural behaviors are modeled by the crane design code (China Standard) [14] based on material mechanics, structural mechanics, and elasticity theory.

CMSs are engaged in busy and heavy work. It must have sufficient strength, stiffness, and stability under complex operating conditions. Their design calculations involve the hyperstatic problem of space structures. Therefore, both the calculating model and design calculation are very complicated. Furthermore, in practical production, structural dimensions are usually taken for integral multiples of millimeters and the specified thickness of the steel plates [15]. Due to these manufacturing limitations the design variables cannot be considered as continuous but should be treated as discrete in a large number of practical design situations, which means that the CMS design optimization is a constrained nonlinear optimization problem with discrete variables, known as NP-complete combinatorial optimization. To solve such problems, recent studies have focused on the development of heuristic optimization techniques, such as genetic algorithms (GAs) [16, 17], particle swarm optimization (PSO) [18-20], ant colony optimization (ACO) [21, 22], big bang-big crunch (BB-BC) $[23,24]$, imperialist competitive algorithm (ICA) [25], and charged system search (CSS) [26]. These algorithms can overcome most of the limitations found in traditional methods, such as becoming trapped in local minima and impractical computational complexity [27, 28]. In view of the simple operation, easy implementation, and the suitability of ACO for computational problems involving discrete variables and combinatorial optimization, the optimization process of BRDO described in this paper is performed using ACO with a mutation local search (ACOM) [29].

Structural reliability can be analyzed using analytical methods, such as first- and second-order second moments (FOSM and SOSM) [30] and advanced first-order second moment (AFOSM) [31], or with simulation methods such as Monte Carlo sampling (MCS) method. The FOSM method is very simple and requires minimal computation effort but sacrifices accuracy for nonlinear limit state functions. The accuracy of the SOSM method is improved compared with that of the FOSM, but its computation effort is greatly increased and this makes it not frequently used in practices. MCS method is accurate; however, it is computationally intensive as it needs a large number of samples to evaluate small failure probabilities. The AFOSM method, a more accurate analytical approach than the FOSM method, is able to efficiently handle low-dimensional uncertainties and nonlinear limit state functions [32] and is applied in most practical cases. It is used to calculate the reliability indices of RBDO in this paper.

The paper is organized as follows. Section 2 outlines the general formulation of discrete RBDO and then Section 3 constructs the RBDO model of an overhead traveling CMS (OTCMS). Section 4 develops the ACOM algorithm used for the optimization process of the RBDO and Section 5 describes the AFOSM method applied for reliability analysis. The RBDO procedure is illustrated in Section 6. Some applied examples that demonstrate the potential of the proposed approach for solving realistic problem are presented in Section 7, followed by concluding remarks in Section 8.

\section{Formulation of Discrete RBDO}

In contrast to deterministic design optimization (DDO), RBDO assumes that quantities related to size, materials, and applied loads of a structure have a random nature to conform to the actual one. The parameters characterizing these quantities are called random variables, and these need to be taken into account in reliability analysis. These random variables may be either random design variables or random parameter variables. In optimization process, the mean values of the random design variables are treated as optimization variables. The formulation of discrete RBDO problem is generally written as follows:

$$
\begin{array}{ll}
\text { Find } & \mathbf{d} \\
\text { minimizing } & f(\mathbf{d}, \mathbf{P}) \\
\text { subject to } & g_{i d}(\mathbf{d}, \mathbf{P}) \leq 0, \quad i d=1, \ldots, N_{1} \\
& R_{j p}=\operatorname{prob}\left(g_{j p}(\mathbf{X}, \mathbf{Y}) \leq 0\right) \geq R_{a, j p}, \\
& j p=1,2, \ldots, N_{2},
\end{array}
$$

where

$$
\mathbf{d}^{\text {lower }} \leq \mathbf{d} \leq \mathbf{d}^{\text {upper }}, \quad \mathbf{d} \in R^{\mathrm{NDV}}, \quad \mathbf{P} \in R^{\mathrm{NPV}} .
$$

$\mathbf{d}=\boldsymbol{\mu}(\mathbf{X})$ and $\mathbf{P}=\boldsymbol{\mu}(\mathbf{Y})$ are the mean value vectors of the random design vector $\mathbf{X}$ and random parameter vector $\mathbf{Y}$, respectively; $f(\mathbf{d}, \mathbf{P})$ is the objective function (i.e., the structure weight or volume); $g_{i d}(\mathbf{d}, \mathbf{P}) \leq 0$ and $R_{a, j p}-\operatorname{prob}\left(g_{j p}(\mathbf{X}, \mathbf{Y}) \leq 0\right) \leq 0$ are the deterministic and probabilistic constraints; $\operatorname{prob}\left(g_{j p}(\mathbf{X}, \mathbf{P}) \leq 0\right)$ denotes the probability of satisfying the $j p$ th performance function $g_{j p}(\mathbf{X}, \mathbf{Y}) \leq 0$ and this probability should be no less than the desired design reliability $R_{a, j p} ; N_{1}, N_{2}$ are the number of deterministic and probabilistic constraints, respectively. d can only take values from a given discrete set $R^{\mathrm{NDV}}$, where NDV and NPV are the number of random design and parameter vectors, respectively. 

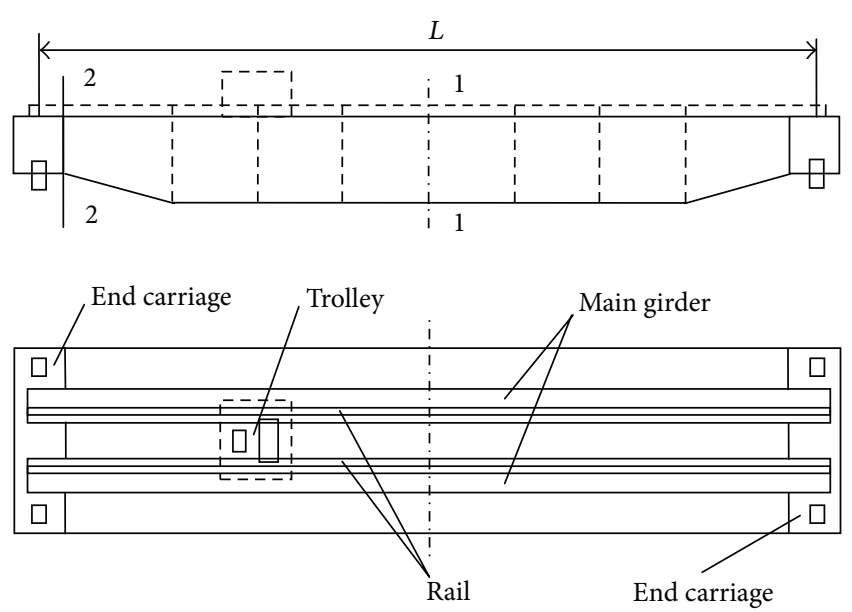

FIgURE 1: Metal structure for overhead travelling crane.

\section{RBDO Modeling of an OTCMS}

Cranes are mechanically applied to moving loads without interfering in activities on the ground. As overhead traveling cranes are the most widely used, a typical OTCMS is selected as the study object. As shown in Figure 1, it is composed of two parallel main girders that span the width of the bay between the runway girders. The OTCMS moves longitudinally, and the two end carriages located on either sides of the span house the wheel blocks. Because the main girders are the principal horizontal beams that support the trolley and are supported by the end carriages, they are the primary load-carrying components and account for more than $80 \%$ of the total weight of the OTCMS. Therefore, the RBDO of OTCMS mainly focuses on the design of these main girders. The crane's solid-web girder is usually a box section fabricated from steel plate, for the main and vice webs, top, and bottom flanges, as shown in Figure 2. Therefore, given a span, its RBDO is to obtain the minimum dead weight, that is, the minimum main girder cross-sectional area, which simultaneously satisfies the required deterministic and probabilistic constraints associated with strength, stiffness, stability, manufacturing process, and dimensional limits [14]. In this paper, a practical bias-rail box main girder is considered. The mathematical model of its RBDO is given in Table 1.

A calculation diagram of section 1-1 of the main girder is shown in Figure 2. Figure 3 is a force diagram for this main girder in the vertical and horizontal planes. In Table 1 and Figures 2 and $3, F_{q}$ represents the uniform load; $P_{G j}(j=$ $1,2, \ldots)$ denotes the concentrated load; $\sum P$ stands for the trolley wheel load applied by the sum of the lifting capacity $P_{Q}$ and trolley weight $P_{G x} ; P_{H}$ and $F_{H}$ represent the horizontal concentrated and uniform inertial load, respectively; $P_{s}$ is the lateral force.

In the RBDO model, the section dimensions are random variables, while their mean values are treated as design variables (see Table 1). The independent uncertain variables include section dimensions and some important parameters (Table 1), and the other parameters are considered to be

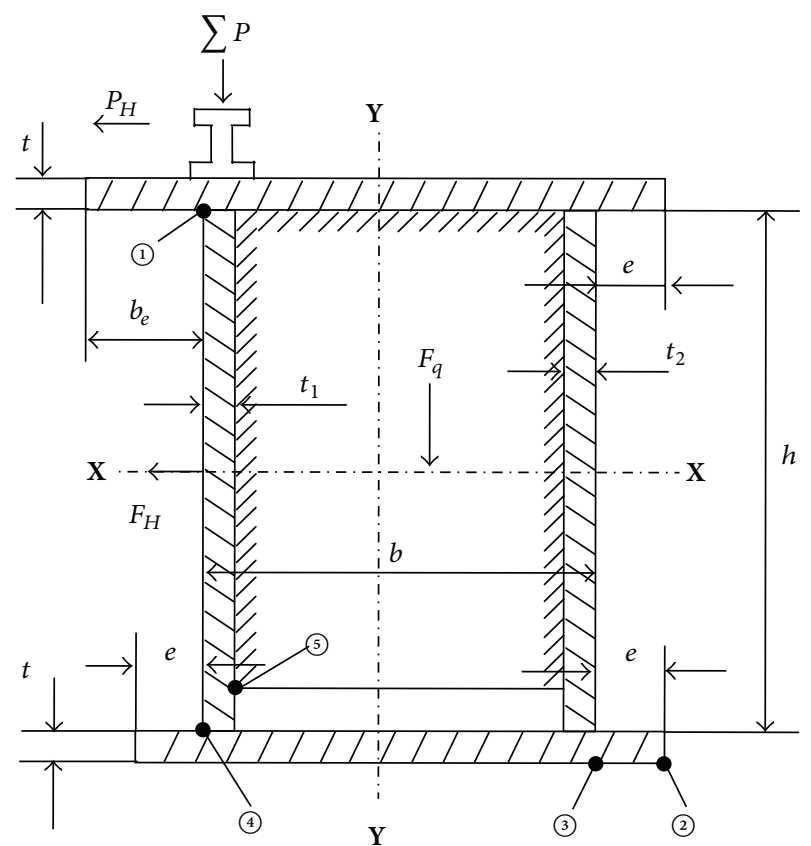

Figure 2: Cross section 1-1 of main girder.

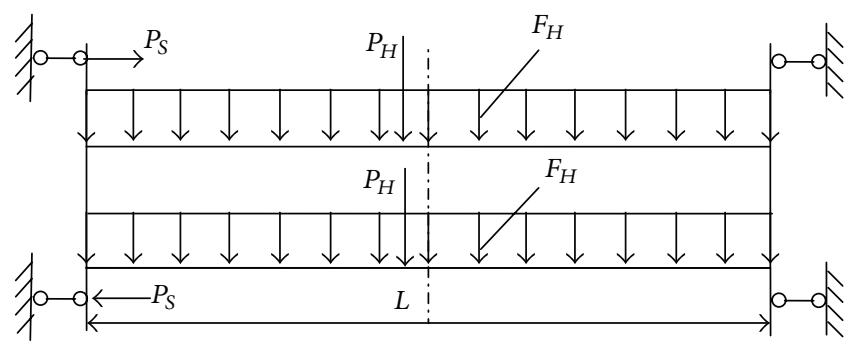

(a) On the horizontal plane

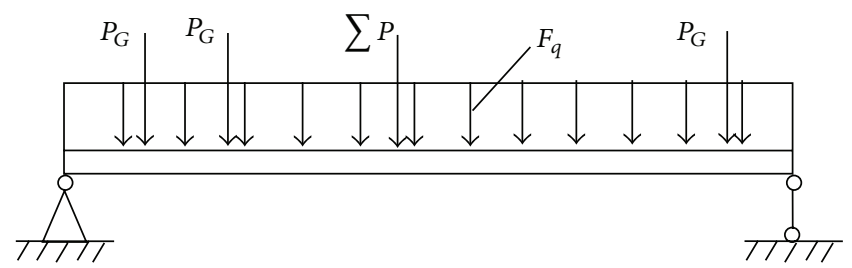

(b) On the vertical plane

FIGURE 3: Force diagram for main girder.

deterministic. It is assumed that all random variables are normally distributed around their mean value. Effects of each random variable on the active constraints at the optimal point are illustrated in Figure 4. The inequality constraints of the RBDO problem define, in turn, the failure by stress, deflection, fatigue, and stiffness. These structural behaviors are described by the assumed limit state functions given in Table 1 [15]. With respect to estimating the most critical configuration of the trolley on the main girder, there are three configurations. (i) The limit state functions $g_{j p}(\mathbf{X}, \mathbf{Y}), j p=$ $1,2,3$ correspond to the position of the maximum bending moment, when a fully loaded trolley is lowering and braking 


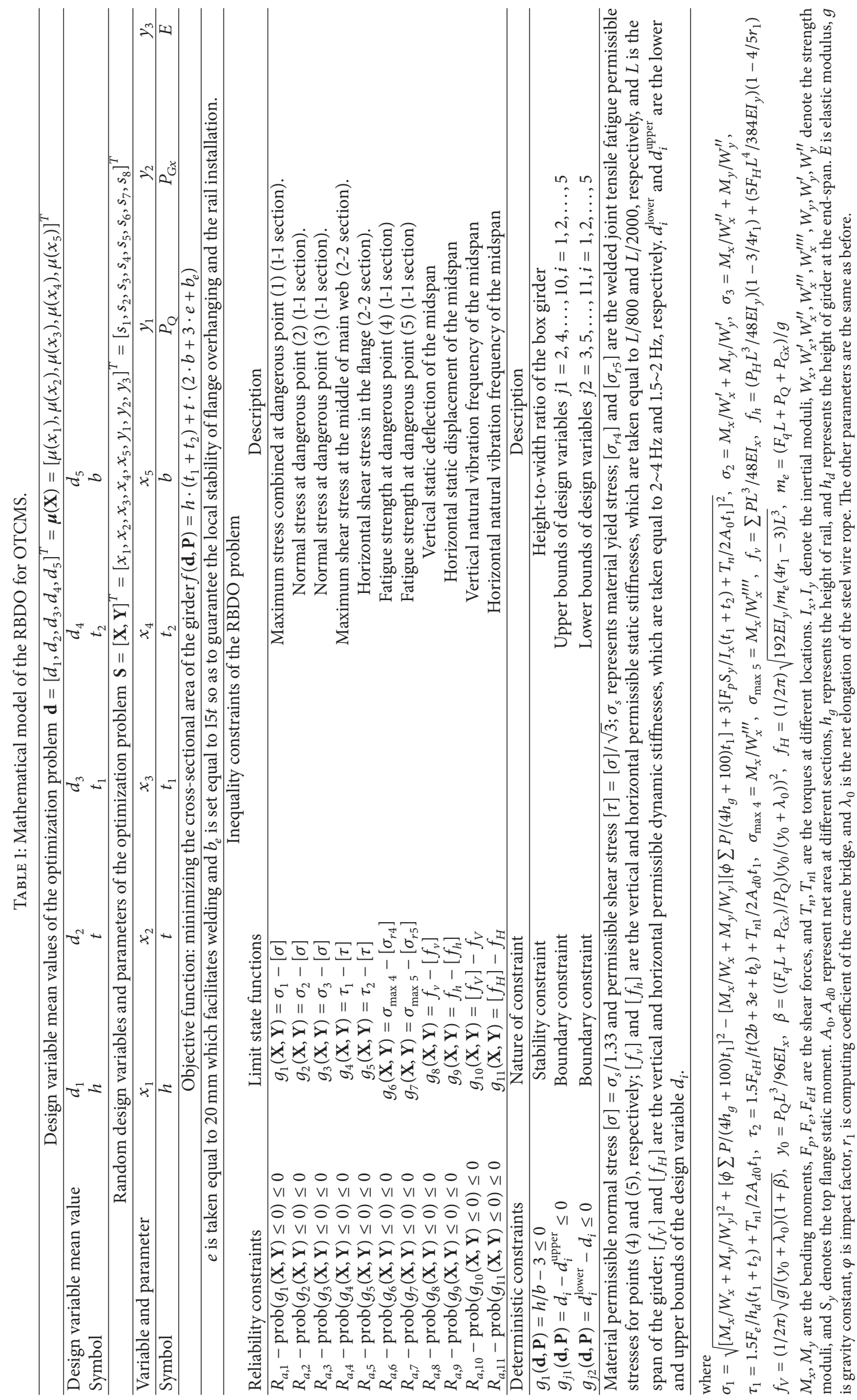



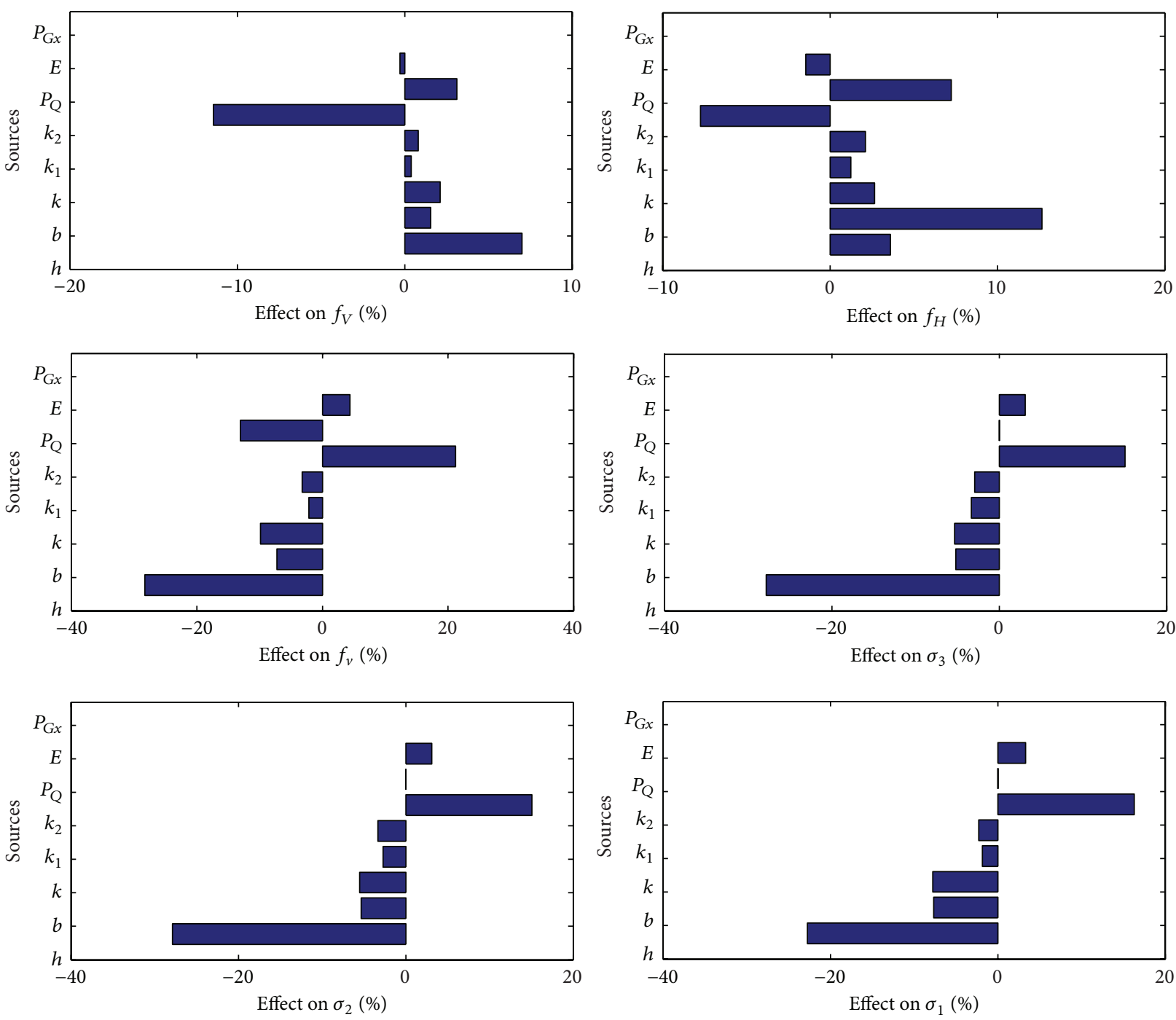

FIGURE 4: Effects of the random variables on the active constraints.

in the midspan and at the same time the crane bridge is starting or braking. (ii) The limit state functions $g_{j p}(\mathbf{X}, \mathbf{Y}), j p=$ 4,5 correspond to the position of the maximum shear stress, when a fully loaded trolley is lowering and braking at the end of the span and at the same time the crane bridge is starting or braking. (iii) The limit state functions $g_{j p}(\mathbf{X}, \mathbf{Y}), j p=9,10,11,12$ correspond to the position of maximum deflection. This is when a fully loaded trolley is positioned in the midspan. The fatigue limit state functions $g_{j p}(\mathbf{X}, \mathbf{Y}), j p=7,8$ correspond to the normal working condition of the crane. The local stability (local buckling) of the main girder can be guaranteed by arranging transverse and longitudinal stiffeners to form the grids according to the width-to-thickness ratio of the flange and the heightto-thickness ratio of the web. Thus, only the global stability of the main girder is considered here. Therefore, the RBDO model of the OTCMS main girder is a five-dimensional optimization problem with 11 deterministic and 11 probabilistic constraints.

\section{The ACO for the OTCMS}

ACO simulates the behavior of real life ant colonies, in which individual ants deposit pheromone along a path while moving from the nest to food sources and vice versa. Thereby, the pheromone trail enables individual to smell and select the optimal routs. The paths with more pheromone are more likely to be selected by other ants, bringing on further amplification of the current pheromone trails and producing a positive feedback process. This behavior forms the shortest path from the nest to the food source and vice versa. The first ACO algorithm, called ant system (AS), was applied to solve the traveling salesman problem. Because the search parallelism of ACO is based on the components of a solution level, it is very efficient. Thus, since the introduction of AS, the ACO metaheuristic has been widely used in many fields $[33,34]$, including for structural optimization, and has shown promising results for various applications. Therefore, ACO is selected as optimization algorithm in the present study. 
4.1. Representation and Initialization of Solution. In our ACO algorithm, each solution is composed of different array elements that correspond to different design variables. One ant's search path represents a solution to the optimization problem or a set of design schemes. The path of the $i$ th ant in the $n$-dimensional search space at iteration $t$ could be denoted by $\mathbf{d}_{i}^{t}(i=1,2, \ldots$, popsize; popsize denotes the population size). Continuous array elements $\operatorname{array}_{j}\left[m_{j}\right]$ are used to store the mean values of the discrete design variable $d_{j}$ in the nondecreasing order $\left(m_{j}\right.$ denotes the array sequence number for the $j$ th design variable mean value $d_{j}$. This is integer with $1 \leq m_{j} \leq M_{j} \cdot j=1,2, \ldots, n$, where $n$ is the number of design variables and $M_{j}$ is the number of discrete values available for $d_{j} . d_{j}^{\text {lower }} \leq d_{j} \leq d_{j}^{\text {upper }}$, where $d_{j}^{\text {lower }}$ and $d_{j}^{\text {upper }}$ are the lower and upper bounds of $d_{j}$ ). Thus, consider

$$
\begin{aligned}
\mathbf{d}_{i}^{t} & =\left\{\operatorname{array}_{1}\left[m_{1}\right], \operatorname{array}_{2}\left[m_{2}\right], \ldots, \operatorname{array}_{n}\left[m_{n}\right]\right\}_{i}^{t} \\
& =\left[d_{1}, d_{2}, \ldots, d_{n}\right]_{i}^{t} .
\end{aligned}
$$

The initial solution is randomly selected. We set the initial pheromone level $\left[T_{j}\left(m_{j}\right)\right]^{0}$ of all array elements in the space to be zero. The heuristic information $\eta_{j}\left(m_{j}\right)$ of array element $\operatorname{array}_{j}\left[m_{j}\right]$ is expressed by (4), so as to induce subsequent solutions to select smaller variable values as far as possible and accelerate optimization process:

$$
\eta_{j}\left[m_{j}\right]=\frac{M_{j}-m_{j}+1}{M_{j}} .
$$

4.2. Selection Probability and Construction of Solutions. As the ants move from node to node to generate paths, they will ceaselessly select the next node from the unvisited neighbor nodes. This process forms the ant paths and, thus, in our algorithm, constructs solutions. In accordance with the transition rule of ant colony system (ACS) [35], each ant begins with the first array element array ${ }_{1}\left[m_{1}\right]$ storing the first design variable mean value $d_{1}$ and selects array elements in proper until $\operatorname{array}_{n}\left[m_{n}\right]$. In this way, a solution is constructed. Hence, for the $i$ th ant on the array element $\operatorname{array}_{j}\left[m_{j}\right]$, the selection probability of the next array element $\operatorname{array}_{k}\left[m_{k}\right]$ is given by

$$
S_{i}(j, k)=\left\{\begin{aligned}
\max _{\operatorname{array}_{k}\left[m_{k}\right] \in J_{k}}\left\{\alpha \cdot T_{k}\left(m_{k}\right)+\xi \cdot \eta_{k}\left(m_{k}\right)\right\}, \\
\text { if } q<q_{0}, \\
p_{i}(j, k), \text { otherwise, }
\end{aligned}\right.
$$

$$
\begin{aligned}
& p_{i}(j, k) \\
& =\left\{\begin{array}{c}
\frac{\alpha \cdot T_{k}\left(m_{k}\right)+\xi \cdot \eta_{k}\left(m_{k}\right)}{\sum_{\text {array }_{k}\left[m_{k}\right] \in J_{k}(r)}\left[\alpha \cdot T_{k}\left(m_{k}\right)+\xi \cdot \eta_{k}\left(m_{k}\right)\right]}, \\
\quad \text { if } \operatorname{array}_{k}\left[m_{k}\right] \in J_{k}, \\
0 \quad \text { otherwise, }
\end{array}\right.
\end{aligned}
$$

where $J_{k}$ is the set of feasible neighbor array elements of $\operatorname{array}_{j}\left[m_{j}\right](k=j+1$ and $k \leq n) . T_{k}\left[m_{k}\right]$ and $\eta_{k}\left(m_{k}\right)$ denote the pheromone intensity and heuristic information on array elements $\operatorname{array}_{k}\left[m_{k}\right]$, respectively. $\alpha$ and $\xi$ give the relative importance of trail $T_{k}\left[m_{k}\right]$ and the heuristic information $\eta_{k}\left(m_{k}\right)$, respectively. Other parameters are as previously described.

4.3. Local Search Based on Mutation Operator. It is well known that ACO easily converges to local optima under positive feedback. A local search can explore the neighborhood and enhance the quality of the solution.

GAs are a powerful tool for solving combinatorial optimization problems. They solve optimization problems using the idea of Darwinian evolution. Basic evolution operations, including crossover, mutation, and selection, make GAs appropriate for performing search. In this paper, the mutation operation is introduced to the proposed algorithm to perform local searches. We assume that the current global optimal solution $\mathbf{d}_{\text {best }}=\left\{\operatorname{array}_{1}\left[m_{1}\right]\right.$, $\operatorname{array}_{2}\left[m_{2}\right], \ldots$, $\left.\operatorname{array}_{n}\left[m_{n}\right]\right\}_{\text {best }}$ has not been improved for a certain number of stagnation generations, sgen. One or more array elements are chosen at random from $\mathbf{d}_{\text {best }}$, and these are changed in a certain manner. Through this mutation operation, we obtain the mutated solution $\mathbf{d}_{\text {best }}^{\prime}$. If $\mathbf{d}_{\text {best }}^{\prime}$ is better than $\mathbf{d}_{\text {best }}$, we replace $\mathbf{d}_{\text {best }}$ with $\mathbf{d}_{\text {best }}^{\prime}$. Otherwise, the global optimal solution remains unchanged.

4.4. Pheromone Updating. The pheromone updating rules of ACO include global updating and local rules. When ant $i$ has finished a path, the pheromone trails on the array elements through which the ant has passed are updated. In this process, the pheromone on the visited array elements is considered to have evaporated, thus increasing the probability that following ants will traverse the other array elements. This process is performed after each ant has found a path; it is a local pheromone update rule with the aim of obtaining more dispersed solutions. The local pheromone update rule is

$$
\begin{array}{r}
{\left[T_{j}\left(m_{j}\right)\right]_{i}^{t+1}=(1-\gamma) \cdot\left[T_{j}\left(m_{j}\right)\right]_{i}^{t},} \\
j=1,2, \ldots, n, \quad 1 \leq m_{j} \leq M_{j} .
\end{array}
$$

When all of the ants have completed their paths (which is called a cycle), a global pheromone update is applied to the array elements passed through by all ants. This process is applied in an iterative mode [29]. The rule is described as follows:

$$
\left[T_{j}\left(m_{j}\right)\right]_{i}^{t+1}=(1-\rho) \cdot\left[T_{j}\left(m_{j}\right)\right]_{i}^{t}+\lambda \cdot F\left(\mathbf{d}_{i}^{t}, \mathbf{P}, \mathbf{X}_{i}^{t}, \mathbf{Y}\right)
$$

where

$\lambda$ $=\left\{\begin{array}{l}c_{1}, \text { if } \operatorname{array}_{j}\left[m_{j}\right] \in \text { the globally (iteratively) best tour, } \\ c_{2}, \text { if } \operatorname{array}_{j}\left[m_{j}\right] \in \text { the iteration worst tour, } \\ c_{3}, \text { otherwise. }\end{array}\right.$ 
$F\left(\mathbf{d}_{i}^{t}, \mathbf{P}, \mathbf{X}_{i}^{t}, \mathbf{Y}\right)$ represents the fitness function value of ant $i$ on the $t$ th iteration (see the next section). $\operatorname{array}_{j}\left[m_{j}\right]$ belongs to the array elements of the path generated by ant $i$ on the $t$ th iteration. $\lambda$ is a phase constant $\left(c_{1} \geq c_{3} \geq c_{2}\right)$ depending on the quality of the solutions to reinforce the pheromone of the best path and evaporate that of the worst. $\gamma \in[0,1]$ and $\rho \in[0,1]$ are the local and global pheromone evaporation rates, respectively. Other parameters are the same as before.

4.5. Evaluation of Solution. The aim of OTCMS RBDO is to develop a design that minimizes the total structure weight while satisfying all deterministic and probabilistic constraints. The ACO algorithm was originally developed for unconstrained optimization problems, and hence it is necessary to somehow incorporate constraints into the ACO algorithm. Constraint-handling techniques have been explored by a number of researchers [36], and commonly employed methods are penalty functions, separation of objectives and constraints, and hybrid methods. Penalty functions are easy to implement and, in particular, are suitable for discrete RBDO. Hence, the penalty function method is selected for constraint handling. The following fitness function is used to transform a constrained RBDO problem to an unconstrained one:

$$
\begin{aligned}
& F(\mathbf{d}, \mathbf{P}, \mathbf{X}, \mathbf{Y}) \\
&=a \cdot \exp \{-c \cdot f(\mathbf{d}, \mathbf{P})-b \\
& \\
&\left.\cdot\left[\sum_{i d=1}^{N_{1}} f_{i d}(\mathbf{d}, \mathbf{P})+\sum_{j p=1}^{N_{2}} f_{j p}(\mathbf{X}, \mathbf{Y})\right]^{2}\right\},
\end{aligned}
$$

where

$$
\begin{gathered}
f_{i d}(\mathbf{d}, \mathbf{P})=\max \left[0, g_{i d}(\mathbf{d}, \mathbf{P})\right], \\
f_{j p}(\mathbf{X}, \mathbf{Y})=\max \left[0, R_{a, j p}-\operatorname{prob}\left(g_{j p}(\mathbf{X}, \mathbf{Y}) \leq 0\right)\right] .
\end{gathered}
$$

$F(\mathbf{d}, \mathbf{P}, \mathbf{X}, \mathbf{Y})$ is unconstrained objective function (the fitness function); $f(\mathbf{d}, \mathbf{P})$ is the original constraint objective function (see (1)); $a, c$, and $b$ are positive problem-specific constants; and $f_{i d}(\mathbf{d}, \mathbf{P}), f_{j p}(\mathbf{X}, \mathbf{Y})$ are penalty functions corresponding to the $i d$ th deterministic and $j p$ th probabilistic, respectively. When satisfied, these penalty functions return to a value of zero; otherwise, the values would be amplified according to the square term in (8). Other parameters are the same as before.

4.6. Termination Criterion. Each run is allowed to continue for a maximum of 100 generations. However, a run may be terminated before this when no improvement in the best objective value is noticed.

\section{Structural Reliability Analysis}

The goal of RBDO is to find the optimal values for a design vector to achieve the target reliability level. In accordance with the RBDO model of OTCMS, randomness in the structure is expressed as the random design vector $\mathbf{X}$ and the random parameter vector $\mathbf{Y}$. The limit state functions $g_{j p}(\mathbf{X}, \mathbf{Y})$, which can represent the stress, displacement, stiffness, and so on, is defined in terms of random vectors $\mathbf{S}$ (define $\mathbf{S} \in(\mathbf{X}, \mathbf{Y})$ ). The limit states that separate the design space into "failure" and "safe" regions are $g_{j p}(\mathbf{X}, \mathbf{Y})=$ 0 . Accordingly, the probability of structural reliability with respect to the $j p$ th limit state function in the specified mode is

$$
\begin{aligned}
R_{j p} & =\operatorname{prob}\left(g_{j p}(\mathbf{X}, \mathbf{Y}) \leq 0\right) \\
& =\operatorname{prob}\left(g_{j p}(\mathbf{S}) \leq 0\right) \\
& =\iint \cdots \int_{D} f_{s}\left(s_{1}, s_{2} \ldots, s_{n}\right) d s_{1} d s_{2} \cdots d s_{n},
\end{aligned}
$$

where $D$ denotes the safe domain $\left(g_{j p}(\mathbf{S}) \leq 0\right)$. $f_{s}\left(s_{1}, s_{2}, \ldots, s_{n}\right)$ is the joint probability density function (PDF) of the random vector $\mathbf{S}$, and $R_{j p}$ can be calculated by integrating the PDF $f_{s}\left(s_{1}, s_{2}, \ldots, s_{n}\right)$ over $D$. Nevertheless, this integral is not a straightforward task, as $f_{s}\left(s_{1}, s_{2}, \ldots, s_{n}\right)$ is not always available. To avoid this calculation, moment methods and simulation techniques can be applied to estimate the probabilistic constraints. FOSM method is broadly used for RBDO applications owing to its effectiveness, efficiency, and simplicity and it was recommended by the Joint Committee of Structural Safety. It solves structural reliability using mean value and standard derivation. At first, the performance function is expanded using the Taylor series at some point; then truncating the series to linear terms, the first-order approximate mean value and standard deviation may be obtained and the reliability index could be solved. Therefore, it is called FOSM. According to the difference of the selected linearization point, FOSM is divided into mean value first-order second moment (MFOSM) (the linearization point is mean value point) and advanced first-order second moment (AFOSM) also called Hasofer-Lind and Rackwitz-Fiessler method (the linearization point is the most probable failure point (MPP)). The advantages of AFOSM are that it is invariant with respect to different failure surface formulations in spaces having the same dimension and more accurate compared with FOSM $[37,38]$. Consequently, the MPP-based AFOSM is used to quantify probabilistic characterization in this research.

AFOSM uses the closest point on the limit state surface to the origin in the standard normal space as a measure of the reliability. The point is called as the design point or MPP $\mathbf{S}^{*}$, and the reliability index $\beta$ is defined as the distance of the design point and the origin, $\beta=\left\|\mathbf{S}^{*}\right\|$, which could be calculated by determining the MPP in random variable space.

Firstly, obtain a linear approximation of the performance function $Z_{j p}=g_{j p}(\mathbf{S})$ by using the first-order Taylor's series expansion about the MPP $\mathbf{S}^{*}$ :

$$
Z \cong g\left(s_{1}^{*}, s_{2}^{*}, \ldots, s_{n}^{*}\right)+\left.\sum_{i=1}^{n}\left(s_{i}-s_{i}^{*}\right) \frac{\partial g}{\partial s_{i}}\right|_{s_{i}^{*}} .
$$


TABLE 2: Main technical characteristics and mechanical properties of the metallic structure.

\begin{tabular}{|c|c|c|c|c|c|}
\hline \multirow{2}{*}{ Lifting capacity } & \multirow{2}{*}{ Lifting height } & \multirow{2}{*}{ Lifting speed } & \multicolumn{3}{|c|}{ Weight } \\
\hline & & & Trolley & $\mathrm{Cab}$ & Traveling mechanism \\
\hline$P_{\mathrm{Q}}=32000 \mathrm{~kg}$ & $H=16 \mathrm{~m}$ & $v_{q}=13 \mathrm{~m} / \mathrm{min}$ & $P_{G x}=11000 \mathrm{~kg}$ & $P_{G 1}=2000 \mathrm{~kg}$ & $P_{G 2}=800 \mathrm{~kg}$ \\
\hline Span length & Trolley velocity & Crane bridge velocity & Yield stress & Poisson's ratio & Elasticity modulus \\
\hline$L=25.5 \mathrm{~m}$ & $v_{x}=45 \mathrm{~m} / \mathrm{min}$ & $v_{d}=90 \mathrm{~m} / \mathrm{min}$ & $\sigma_{s}=235 \mathrm{MPa}$ & $v=0.3$ & $E=2.11 \times 10^{11} \mathrm{~Pa}$ \\
\hline
\end{tabular}

Since the MPP $\mathbf{S}^{*}$ is on the limit state surface, the limit state function equals zero $g\left(s_{1}^{*}, s_{2}^{*}, \ldots, s_{n}^{*}\right)=0$. Here the subscript $j p$ has been dropped for the sake of simplicity of the subsequent notation.

$Z$ 's mean value $\mu_{Z}$ and standard deviation $\sigma_{Z}$ could be expressed as follows:

$$
\begin{gathered}
\left.\mu_{Z} \cong \sum_{i=1}^{n}\left(\mu_{s_{i}}-s_{i}^{*}\right) \frac{\partial g}{\partial s_{i}}\right|_{s_{i}^{*}}, \\
\sigma_{Z}=\sqrt{\left.\sum_{i=1}^{n}\left(\frac{\partial g}{\partial s_{i}}\right)^{2}\right|_{s_{i}^{*}} \sigma_{s_{i}}^{2}} .
\end{gathered}
$$

The reliability index $\beta$ is shown as

$$
\beta=\frac{\mu_{Z}}{\sigma_{Z}}=\frac{\left.\sum_{i=1}^{n}\left(\mu_{s_{i}}-s_{i}^{*}\right)\left(\partial g / \partial s_{i}\right)\right|_{s_{i}^{*}}}{\left.\sum_{i=1}^{n} \alpha_{i} \sigma_{s_{i}}\left(\partial g / \partial s_{i}\right)\right|_{s_{i}^{*}}},
$$

where

$$
\alpha_{i}=\frac{\left.\sigma_{s_{i}}\left(\partial g / \partial s_{i}\right)\right|_{s_{i}^{*}}}{\left[\left.\sum_{i=1}^{n}\left(\partial g / \partial s_{i}\right)^{2}\right|_{s_{i}^{*}} \sigma_{s_{i}}^{2}\right]^{1 / 2}} .
$$

Then

$$
\mu_{s_{i}}-s_{i}^{*}-\beta \alpha_{i} \sigma_{s_{i}}=0
$$

Finally, combining (13), (15), and the limit state function $g(\mathbf{S})=0$, the MPP $s_{i}^{*}$ and reliability index $\beta$ could be calculated by an iterative procedure. Then, the reliability $R$ could be approximated by $R=\Phi(\beta)$ where $\Phi(\cdot)$ is the standard normal cumulative distribution function. Here, random variables $s_{i}(i=1,2, \ldots, n)$ are assumed to be normal distribution and are independent to each other and the same assumption will be used throughout this paper.

\section{RBDO Procedure}

Using the methods described in the previous sections, the RBDO numerical procedure illustrated in Figure 5 was developed.

\section{Example of Reliability-Based Design Optimization}

The proposed approach was coded in $\mathrm{C}++$ and executed on 2.26 GHz Intel Dual Core processor and $1 \mathrm{~GB}$ main memory.
TABLE 3: Statistical properties of the random variables $s_{i}$.

\begin{tabular}{lccc}
\hline Random variable & Distribution & Mean value $(\mu)$ & COV $(\sigma / \mu)$ \\
\hline Lifting capacity $\left(P_{\mathrm{Q}}\right)$ & Normal & $32000 \mathrm{~kg}$ & 0.10 \\
Trolley weight $\left(P_{G x}\right)$ & Normal & $11000 \mathrm{~kg}$ & 0.05 \\
Elasticity modulus $(E)$ & Normal & $2.11 \times 10^{11} \mathrm{~Pa}$ & 0.05 \\
Design variables $\left(d_{i}\right)$ & Normal & $d_{i} \mathrm{~mm}$ & 0.05 \\
\hline
\end{tabular}

TABLE 4: Parameter values used in adopted ACO.

\begin{tabular}{lc}
\hline Parameters & Values for the example \\
\hline Fitness function parameters & $a=100, c=10^{-6}, b=10$ \\
Number of ants & Popsize $=40$ \\
Maximum number of iterations & mgen $=500$ \\
Fixed nonevolution generation & sgen $=5$ or 10 \\
Pheromone updating rule parameter & $\rho=0.2, \gamma=0.4$ \\
Selection probability parameters & $\alpha=1, \beta=1$ \\
Phase constants & $c 1=2, c 2=0, c 3=1$ \\
Transition rule parameter & $q_{0}=0.9$ \\
\hline
\end{tabular}

7.1. Design Parameters. The proposed RBDO method was applied to the design of a real-world OTCMS with a working class of A6. Its main technical characteristics and mechanical properties are presented in Table 2. The upper and lower bounds of the design vectors were taken to be $\mathbf{d}^{\text {upper }}=$ $\{1820,40,40,40,995\}$ and $\mathbf{d}^{\text {lower }}=\{1500,6,6,6,500\}$ (units in $\mathrm{mm}$ ). In practical design, the main girder height and width are usually designed as integer multiples of $5 \mathrm{~mm}$, so the number of discrete mean values available for the design variables (main girder height and width) was $M_{1}=65$ and $M_{5}=100$. The step size intervals were set to be $0.5 \mathrm{~mm}$ for web and flange thicknesses of less than $30 \mathrm{~mm}$ and to be $1 \mathrm{~mm}$ for thicknesses more than $30 \mathrm{~mm}$ [15]. Thus, the number of discrete mean values available for the design variables (thicknesses of main web, vice web, and flange) was $M_{2}=M_{3}=M_{4}=60$. The statistical properties of the random variables are summarized in Table 3. For the desired reliability probabilities, we refer to JCSS [39] and the current crane design code [14]; a value of 0.979 was set for $g_{1}(\mathbf{X}, \mathbf{Y})$ to $g_{7}(\mathbf{X}, \mathbf{Y}), 0.968$ for $g_{8}(\mathbf{X}, \mathbf{Y})$ and $g_{9}(\mathbf{X}, \mathbf{Y})$, and 0.759 for $g_{10}(\mathbf{X}, \mathbf{Y})$ and $g_{11}(\mathbf{X}, \mathbf{Y})$. It should be noted that these target reliabilities serve only as examples to illustrate the proposed $\mathrm{RBDO}$ approach and are not recommended design values. By means of a large number of trials and experience, the parameter values of the constructed ACO algorithm were set in Table 4. 


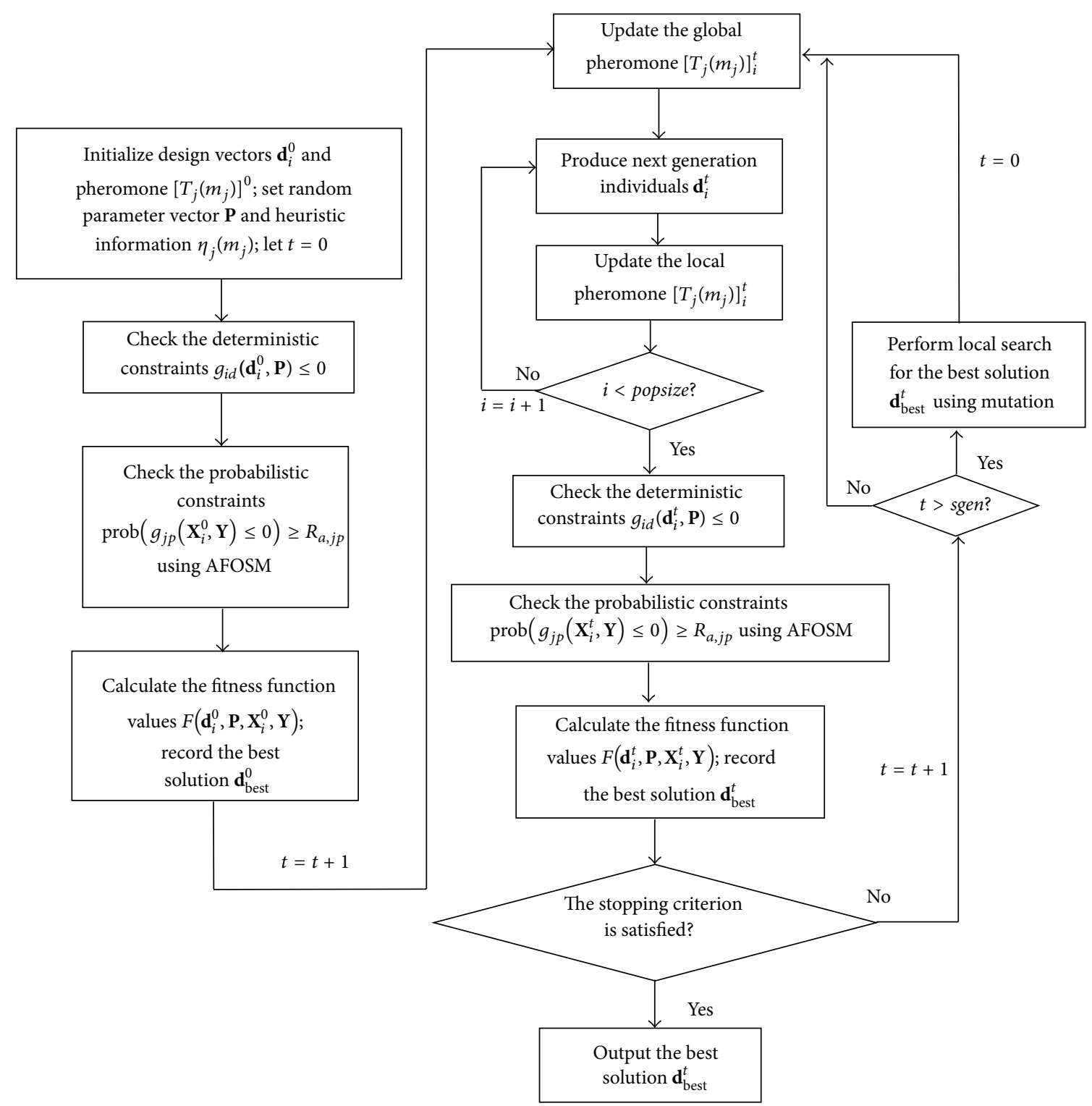

FIGURE 5: Numerical procedure of RBDO.

TABLE 5: Optimization results.

\begin{tabular}{lcccccccc}
\hline \multirow{2}{*}{ Solution } & \multicolumn{4}{c}{ Optimization variable $(\mathrm{mm})$} & \multicolumn{2}{c}{ Objective and fitness function } & Generation & Time (s) \\
& $d_{1}$ & $d_{2}$ & $d_{3}$ & $d_{4}$ & $d_{5}$ & $f(\mathbf{d}, \mathbf{P})\left(\mathrm{mm}^{2}\right)$ & $F(\mathbf{d}, \mathbf{P}, \mathbf{X}, \mathbf{Y})$ & - \\
PD & 1600 & 10 & 8 & 6 & 760 & 39700 & 96.1078 & - \\
DDO & 1765 & 7 & 6 & 6 & 610 & 30875 & 96.9597 & 58 \\
RBDO & 1815 & 7.5 & 6.5 & 6 & 785 & 35756 & 96.4875 & 23 \\
\hline
\end{tabular}

PD stands for practical design.

7.2. RBDO Results. Some final points concerning the practical design and the deterministic and reliability-based optimization process are given in Table 5. Table 6 shows the performance and reliability with respect to each optimum design. Variations in the number of iterations required for the reliability indices of active constraints and cross-sectional area to converge are illustrated in Figure 6.
Tables 5 and 6 show that the deterministic design took 58 generations to find the optimum area of $30875 \mathrm{~mm}^{2}$, which is about $8825 \mathrm{~mm}^{2}$ less than that of the practical design. Thus, the deterministic optimization found a better solution within just $0.1794 \mathrm{~s}$. The critical constraint of the optimum design is the vertical natural vibration frequency $f_{V}$ at the midspan point. The corresponding constraint value is $2.00067 \mathrm{~Hz}$, 
TABLE 6: The performance and reliability with respect to optimum designs.

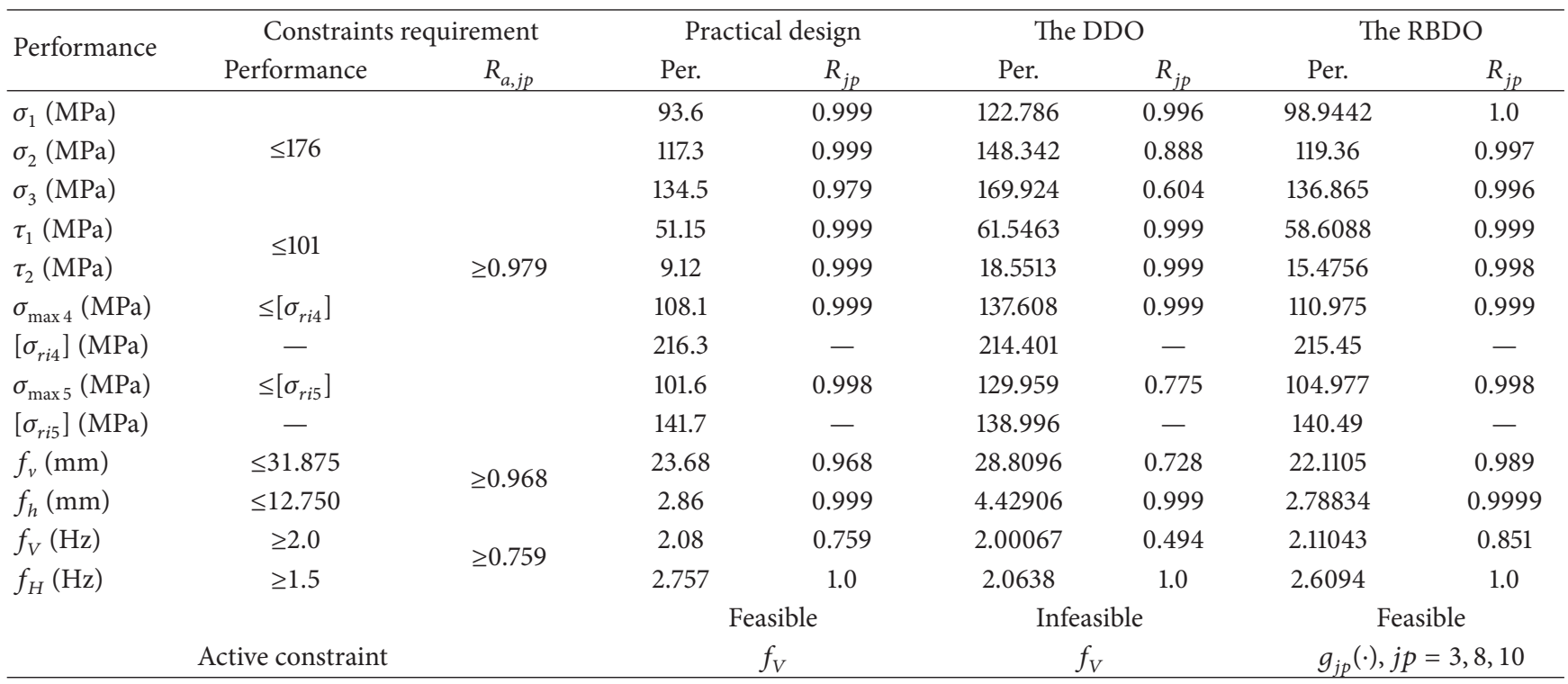

Per. stands for performance.

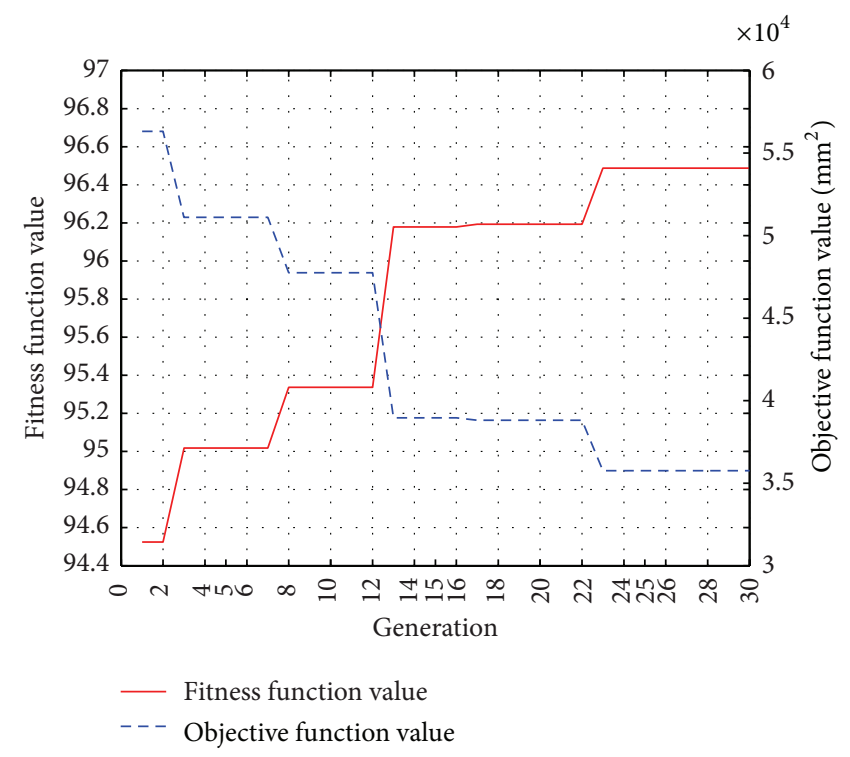

(a)

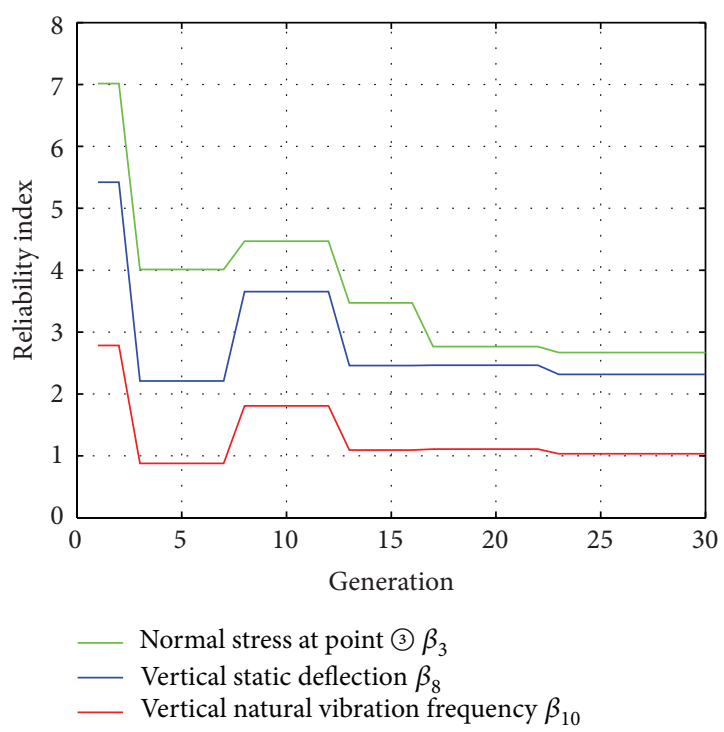

(b)

FIGURE 6: Convergence histories for the RBDO of the OTCMS, (a) for objective and fitness function and (b) for reliability indices of active constraints $\left(g_{j p}(\cdot), j p=3,8,10\right)$.

which is higher than the required value $2 \mathrm{~Hz}$, and satisfies the performance requirement. Probabilistic analyses were also conducted for this deterministic optimum and the practical design; the results are shown in Table 6 . The active constraints of the deterministic optimum have reliabilities of 0.604 , 0.728 , and 0.494 , which are all below the desired reliabilities of $0.979,0.968$, and 0.759 , respectively. The results indicate that the DDO can significantly reduce the structural area, but its ability to meet the design requirements for reliability under uncertainties is quite low. To obtain a more reliable design by considering uncertainties during the optimization process, RBDO is needed.

As shown in Tables 5 and 6, RBDO required 23 optimization iterations. The reliabilities of the active constraints at the optimum point are $0.996,0.989$, and 0.851 (corresponding to reliability indices $\beta_{3}=2.67, \beta_{8}=2.32$, and $\beta_{10}=1.04$ ), which are all above the desired reliabilities of $0.979,0.968$, and 0.759. Compared with DDO, the final area given by the RBDO process increases from 30875 to $35756 \mathrm{~mm}^{2}$ (an increase of $15.9 \%$ ), and the CPU time is one order of magnitude more 
than that of DDO. However, the reliability of the RBDO results exhibits a significant increase and meets the desired levels. Therefore, considering the inherent uncertainties in material, dimensions, and loads, only the final RBDO design is both feasible and safe.

\section{Conclusions}

This paper presented an RBDO methodology that combines ACOM and AFOSM. This was applied to the design of a real-world OTCMS under uncertainties in loads, crosssectional dimensions, and materials for the first time. The design procedure directly couples structural performance calculation, numerical design optimization, and structural reliability analysis while considering different modes of failure in the OTCMS. From the results obtained, the following conclusions could be drawn. The deterministic optimization method can improve design quality and efficiency; nevertheless, it is more likely to lead to unreliable solutions once we consider uncertainty. On the contrary, RBDO can achieve a more compromised design that balances economic and safety. The inherent nature of uncertain factors in the design of CMSs means that RBDO is a more realistic design method. It is worth noting that, in such high-risk equipment, an increase in the reliability that leads to a cost decrement is financially much more beneficial rather than increasing the weight which results in the cost increments on a long view. The constructed approach is applicable and efficient for OTCMSs RBDO and might also be useful for other metallic structures with more design and random variables, as well as multiple objectives. This will be studied in a future work.

\section{Conflict of Interests}

The authors declare that there is no conflict of interests regarding the publication of this paper.

\section{Acknowledgment}

This work was supported by the National Natural Science Foundation of China under Grant no. 51275329.

\section{References}

[1] C. B. Pinca, G. O. Tirian, A. V. Socalici, and E. D. Ardelean, "Dimensional optimization for the strength structure of a traveling crane," WSEAS Transactions on Applied and Theoretical Mechanics, vol. 4, no. 4, pp. 147-156, 2009.

[2] N. D. Lagaros and M. Papadrakakis, "Applied soft computing for optimum design of structures," Structural and Multidisciplinary Optimization, vol. 45, no. 6, pp. 787-799, 2012.

[3] R. Mijailović and G. Kastratović, "Cross-section optimization of tower crane lattice boom," Meccanica, vol. 44, no. 5, pp. 599-611, 2009.

[4] K. Jármai, "Decision support system on IBM PC for design of economic steel structures applied to crane girders," Thin-Walled Structures, vol. 10, no. 2, pp. 143-159, 1990.
[5] C. Seeßelberg, "About the cross-section optimization of welded profiles of run-way beams for top mounted overhead cranes," Stahlbau, vol. 72, no. 9, pp. 636-645, 2003.

[6] C. Sun, Y. Tan, J. C. Zeng, J. S. Pan, and Y. F. Tao, “The structure optimization of main beam for bridge crane based on an improved PSO," Journal of Computers, vol. 6, no. 8, pp. 15851590, 2011.

[7] G. Sun, G. Li, S. Zhou, H. Li, S. Hou, and Q. Li, "Crashworthiness design of vehicle by using multiobjective robust optimization," Structural and Multidisciplinary Optimization, vol. 44, no. 1, pp. 99-110, 2011.

[8] N. D. Lagaros, V. Plevris, and M. Papadrakakis, "Neurocomputing strategies for solving reliability-robust design optimization problems," Engineering Computations, vol. 27, no. 7, pp. 819-840, 2010.

[9] L. Yu, Y. Cao, Q. Chong, and X. Wu, "Reliability-based design for the structure of tower crane under aleatory and epistemic uncertainties," in Proceedings of the International Conference on Quality, Reliability, Risk, Maintenance, and Safety Engineering (ICQR2MSE '11), pp. 938-943, June 2011.

[10] W. Meng, Z. Yang, X. Qi, and J. Cai, "Reliability analysisbased numerical calculation of metal structure of bridge crane," Mathematical Problems in Engineering, vol. 2013, Article ID 260976, 5 pages, 2013.

[11] R. Jafar and E. Masoud, "Latin hypercube sampling applied to reliability-based multidisciplinary design optimization of a launch vehicle," Aerospace Science and Technology, vol. 28, no. 1, pp. 297-304, 2013.

[12] J. Fang, Y. Gao, G. Sun, and Q. Li, "Multiobjective reliabilitybased optimization for design of a vehicle door," Finite Elements in Analysis and Design, vol. 67, pp. 13-21, 2013.

[13] H. M. Gomes, A. M. Awruch, and P. A. M. Lopes, "Reliability based optimization of laminated composite structures using genetic algorithms and Artificial Neural Networks," Structural Safety, vol. 33, no. 3, pp. 186-195, 2011.

[14] L. Wan, G. N. Xu, and D. M. Gu, “Design rules for cranes," Tech. Rep. GB/T3811-2008, China Standards Press, Beijing, China, 2008.

[15] Y. F. Tang, X. H. Wang, and Z. M. Pu, Dimension Shape Weight and Tolerances for Hot-Rolled Steel Plates and Sheet, (GB/T 7092006), China Standards Press, Beijing, China, 2007.

[16] A. Kaveh and V. Kalatjari, "Genetic algorithm for discrete-sizing optimal design of trusses using the force method," International Journal for Numerical Methods in Engineering, vol. 55, no. 1, pp. 55-72, 2002.

[17] A. Kaveh and A. Abdietehrani, "Design of frames using genetic algorithm, force method and graph theory," International Journal for Numerical Methods in Engineering, vol. 61, no. 14, pp. 2555-2565, 2004.

[18] G.-C. Luh and C.-Y. Lin, "Optimal design of truss-structures using particle swarm optimization," Computers \& Structures, vol. 89, no. 23-24, pp. 2221-2232, 2011.

[19] C. K. Dimou and V. K. Koumousis, "Reliability-based optimal design of truss structures using particle swarm optimization," Journal of Computing in Civil Engineering, vol. 23, no. 2, pp. 100109, 2009.

[20] A. Xiao, B. Wang, C. Sun, S. Zhang, and Z. Yang, "Fitness estimation based particle swarm optimization algorithm for layout design of truss structures," Mathematical Problems in Engineering, vol. 2014, Article ID 671872, 11 pages, 2014. 
[21] C. V. Camp, B. J. Bichon, and S. P. Stovall, "Design of steel frames using ant colony optimization," Journal of Structural Engineering, vol. 131, no. 3, pp. 369-379, 2005.

[22] A. Kaveh and S. Talatahari, "An improved ant colony optimization for the design of planar steel frames," Engineering Structures, vol. 32, no. 3, pp. 864-873, 2010.

[23] O. Hasancebi and S. Kazemzadeh Azad, "Discrete size optimization of steel trusses using a refined big bang-big crunch algorithm," Engineering Optimization, vol. 46, no. 1, pp. 61-83, 2014.

[24] A. Kaveh and S. Talatahari, "Size optimization of space trusses using Big Bang-Big Crunch algorithm," Computers and Structures, vol. 87, no. 17-18, pp. 1129-1140, 2009.

[25] A. Kaveh and S. Talatahari, "Optimum design of skeletal structures using imperialist competitive algorithm," Computers and Structures, vol. 88, no. 21-22, pp. 1220-1229, 2010.

[26] A. Kaveh and S. Talatahari, "Optimal design of skeletal structures via the charged system search algorithm," Structural and Multidisciplinary Optimization, vol. 41, no. 6, pp. 893-911, 2010.

[27] J. A. Momoh, R. Adapa, and M. E. El-Hawary, "A review of selected optimal power flow literature to 1993. I. Nonlinear and quadratic programming approaches," IEEE Transactions on Power Systems, vol. 14, no. 1, pp. 96-104, 1999.

[28] J. A. Monoh, M. E. EI-Hawary, and R. Adapa, "A review of selected optimal power flow literature to 1993. Part II. Newton, linear programming and Interior Point Methods," IEEE Transactions on Power Systems, vol. 14, no. 1, pp. 105-111, 1999.

[29] X. Fan, Y. Lin, and Z. Ji, "Ship pipe routing design using the ACO with iterative pheromone updating," Journal of Ship Production, vol. 23, no. 1, pp. 36-45, 2007.

[30] O. Ditlevsen and H. O. Madsen, Structural Reliability Methods, Wiley, Chichester, UK, 1996.

[31] Y. T. Wu, H. R. Millwater, and T. A. Cruse, "Advanced probabilistic structural analysis method for implicit performance functions," AIAA Journal, vol. 28, no. 9, pp. 1663-1669, 1990.

[32] Y.-P. Wang, Z.-Z. Lu, and Z.-F. Yue, "Reliability analysis for implicit limit state equation," Applied Mathematics and Mechanics (English Edition), vol. 26, no. 9, pp. 1158-1164, 2005.

[33] H. Hemmatian, A. Fereidoon, A. Sadollah, and A. Bahreininejad, "Optimization of laminate stacking sequence for minimizing weight and cost using elitist ant system optimization," Advances in Engineering Software, vol. 57, no. 3, pp. 8-18, 2013.

[34] A. Kaveh and S. Talatahari, "Particle swarm optimizer, ant colony strategy and harmony search scheme hybridized for optimization of truss structures," Computers and Structures, vol. 87, no. 5-6, pp. 267-283, 2009.

[35] M. Dorigo and L. M. Gambardella, "Ant colony system: a cooperative learning approach to the traveling salesman problem," IEEE Transactions on Evolutionary Computation, vol. 1, no. 1, pp. 53-66, 1997.

[36] P. W. Jansen and R. E. Perez, "Constrained structural design optimization via a parallel augmented Lagrangian particle swarm optimization approach," Computers and Structures, vol. 89, no. 13-14, pp. 1352-1366, 2011.

[37] A. M. Hasofer and N. C. Lind, "Exact and invariant secondmoment code format," Journal Engineering Mechanics DivisionASCE, vol. 100, no. 1, pp. 111-121, 1974.

[38] R. Rackwitz and B. Flessler, "Structural reliability under combined random load sequences," Computers and Structures, vol. 9, no. 5, pp. 489-494, 1978.
[39] JCSS: Probabilistic Model Code, "The Joint Committee on Structural Safety," http://www.jcss.ethz,ch,2. 


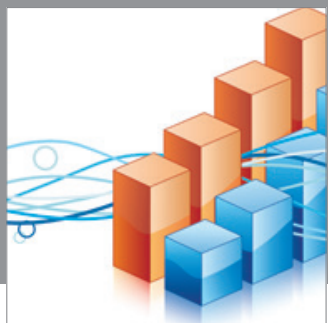

Advances in

Operations Research

mansans

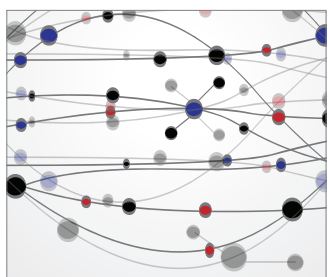

The Scientific World Journal
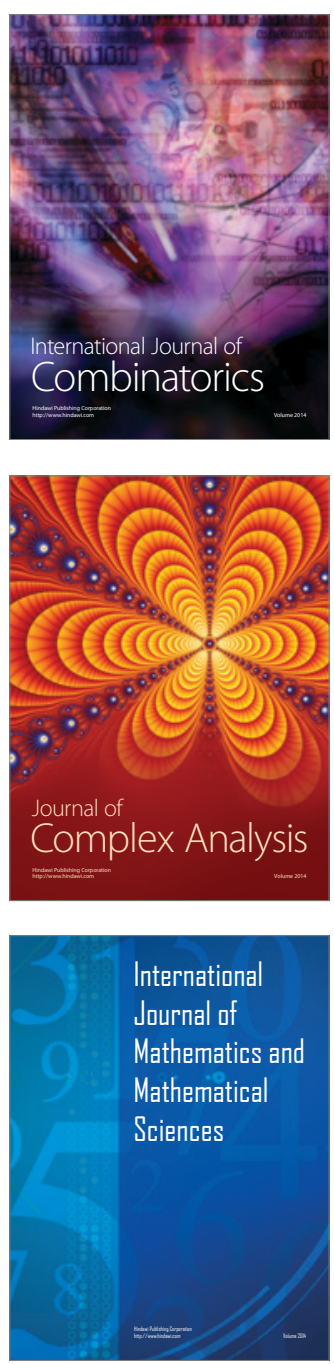
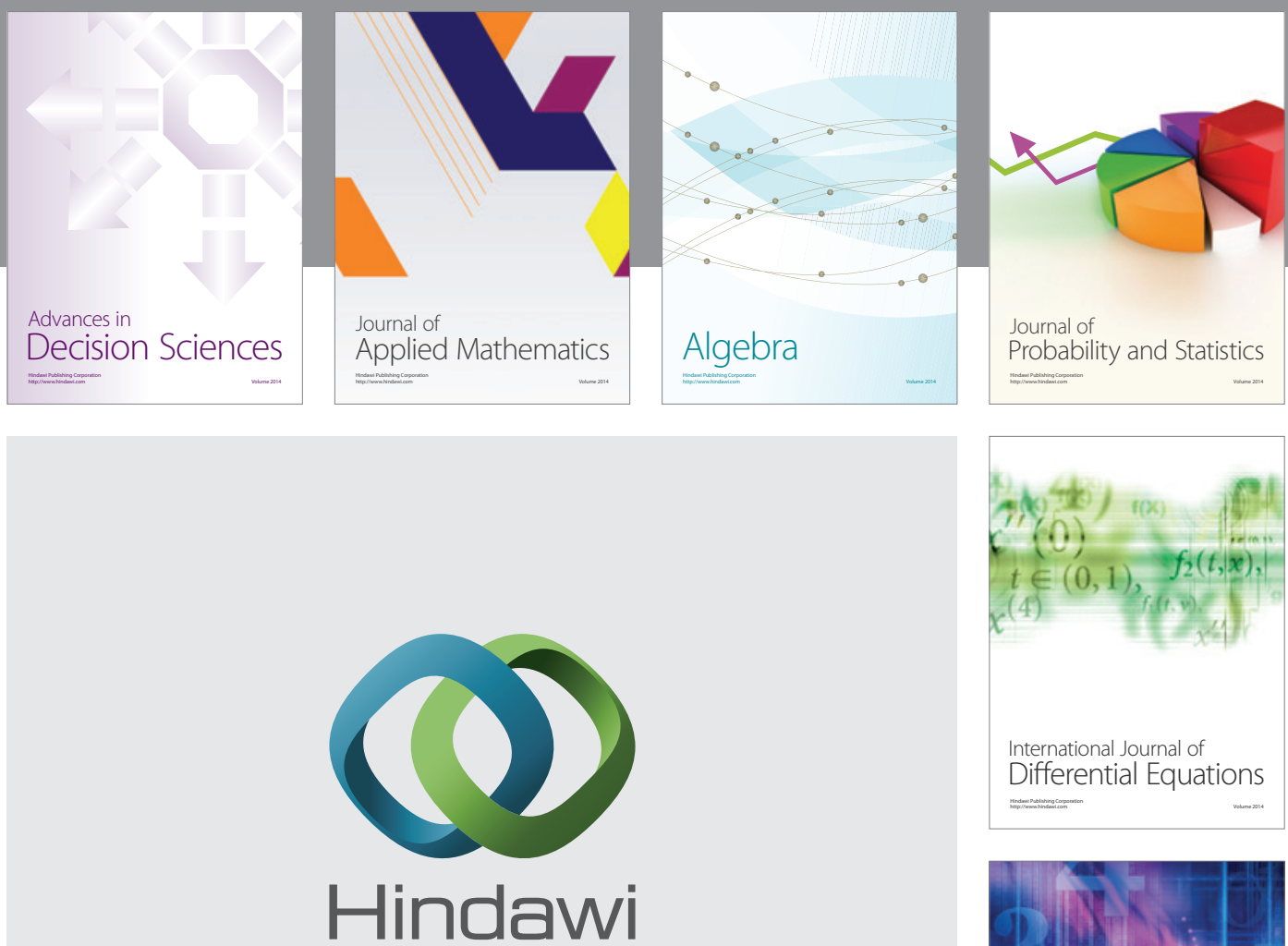

Submit your manuscripts at http://www.hindawi.com
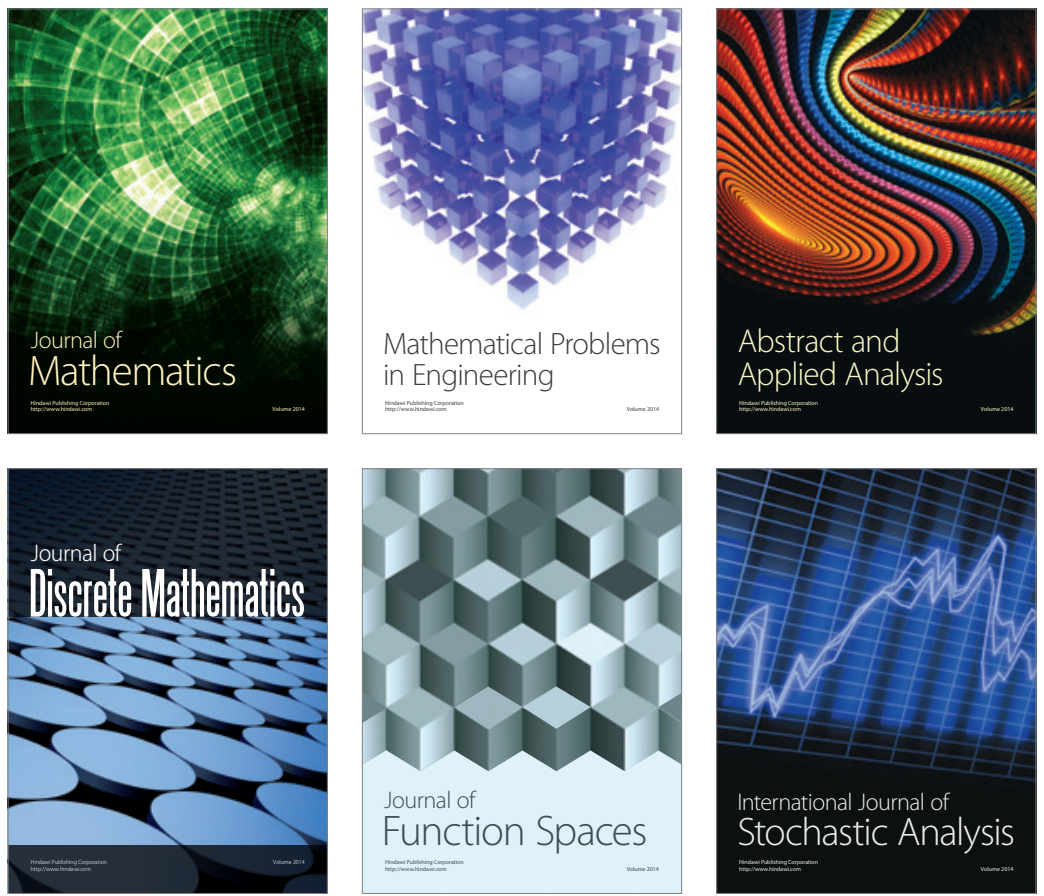

Journal of

Function Spaces

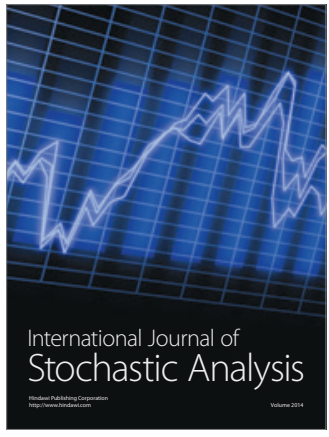

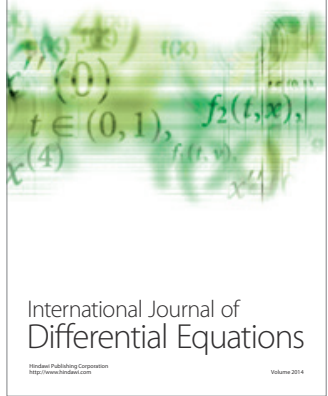
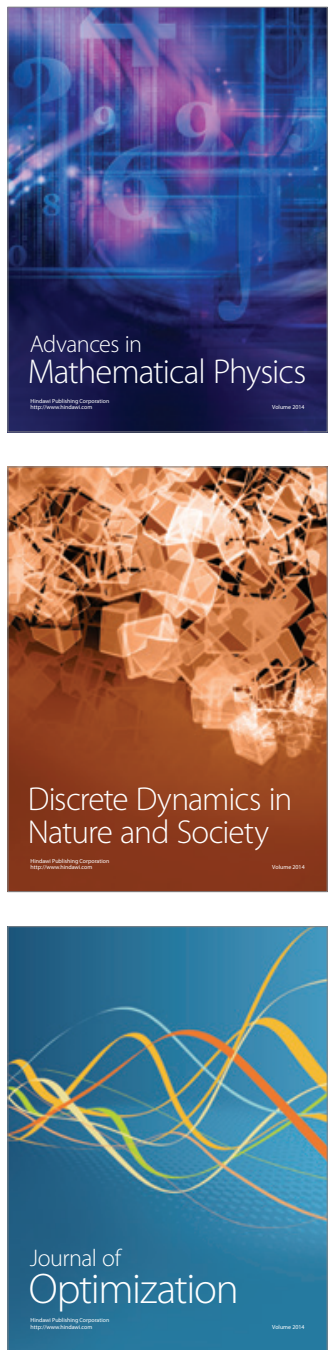